\title{
CONCEITOS DE GESTÃO DE MARCA: COMPARATIVOS ENTRE AS VISÕES APRESENTADAS POR LINDSTROM, MESHER E WHEELER
}

\author{
Arina Blum \\ Universidade Federal de Santa Catarina \\ arinablum@gmail.com \\ Taís Vieira Pereira \\ Faculdades Integradas de Taquara \\ taisvp@gmail.com \\ Vanessa Neto Bischoff \\ Faculdade América Latina \\ vanessa@vanessabischoff.com.br
}

\begin{abstract}
Resumo: Marca, ou brand, abarca fatores de propriedade somados à responsabilidade e aos atos de cuidado que recaem sobre ela. O termo brand deu origem ao chamado "branding" por justamente fazer menção à carga de direitos e deveres atribuídos a um dono. Por meio de uma pesquisa qualitativa de revisão bibliográfica nas áreas do design e do marketing, mais especificamente acerca do branding como gestão de marca, este artigo apresenta as visões de Lindstrom, Mesher e Wheeler sobre o tema, considerando a hipótese de que os três autores apresentam conceitos que se convergem, embora os seus escritos tenham focos diferentes. O objetivo do estudo aqui relatado é, a partir da relação entre as ideias afins dos três autores, extrair conceitos que constituam ideais no campo do branding. Os resultados indicam seis apontamentos que fazem a interação entre os autores analisados.
\end{abstract}

Palavras-chave: design, marketing, identidade, marca, gestão de marca.

Abstract: Brand includes property factors and acts of care together that define it. The term "brand" originated the called "branding" by just to mention the burden of rights and duties assigned to its owner. Through a literature review of qualitative research in the areas of design and marketing, more specifically about branding and brand management, this article presents the views of Lindstrom, Mesher and Wheeler on the subject, considering the hypothesis that the three authors introduce concepts that converge, eventhough their writings have different focus. The objective of the study reported here is based on the relationship between the three likeminded authors, extract concepts which are ideal in the field of branding. 
The results indicate six notes that make the interaction between the authors analyzed.

Keywords: design, marketing, identity, brand, branding.

\section{INTRODUÇÃO}

Branding e marca são termos que se correlacionam. Para Strunck (2012), branding faz menção à carga de direitos e deveres atribuídos a um dono. A propriedade e toda a responsabilidade e os atos de cuidado que recaem sobre esta são fatores concernentes a uma marca ou brand. Silva (2002) afirma que a ideia de branding vem de uma evolução do marketing corporativo - o responsável por determinar o gerenciamento das marcas - e, muito mais do que um planejamento da marca, o branding se configura na relação de afetividade desta com o seu público. Cameira (2013) corrobora com essa ideia ao afirmar que a própria criação da marca ideia que ultrapassa os meandros estritamente visuais - evoluiu para a direção da identidade corporativa e, mais recentemente, para o branding - a gestão da marca.

A partir do embasamento de que "na pesquisa qualitativa, o pesquisador utiliza os insights e as informações provenientes da literatura enquanto conhecimento sobre o contexto" (FLICK, 2009, p. 62), o presente artigo se baseia na hipótese de que três autores que apresentam enfoques distintos sobre gestão de marcas - Lindstrom (2007), Mesher (2011) e Wheeler (2008) - convergem quanto a alguns conceitos que explanam. Por meio de uma pesquisa de revisão bibliográfica, o objetivo deste artigo concentrou-se em confrontar seus textos com a intenção de extrair conceitos afins que constituam ideais no campo do branding.

A escolha desses autores deu-se pela abordagem que os mesmos fazem à gestão de marca, tendo, no entanto, diferentes focos: Lindstrom volta-se aos aspectos sensoriais da marca; Mesher expõe sobre aplicação da marca em ambientes comerciais; Wheeler, por sua vez, enfatiza a construção da identidade visual da marca. A busca proposital por enfoques diferenciados teve como objetivo conferir visões mais amplas quanto ao contexto de branding e, assim, promover discussões que contribuam para os estudos nesta área.

\section{BRANDING COMO GESTÃO DE MARCA}

Silva $(2002$, p.13) reuniu uma série conceitos sobre branding e a sua relação com a ideia de marca, entre eles: "Branding é um processo de construção de gerenciamento de marca" (Luciano Deos); "Branding é a ampliação da importância da marca como elemento diferenciador em um mercado em que a tecnologia não ocupa mais esse papel" (Ronald Kapaz); "Branding é uma forma de desenvolver uma construção de marca aplicada no pré-design e no pós-design" (Bill Martinez); "Branding é uma palavra que os clientes estão usando e o que a gente está procurando fazer entender [...] para poder atender às expectativas do cliente e do mercado" (Luiz Roberto Farina); "Branding é uma questão de vivência e afetividade para se desenvolver a fidelidade da marca pelo cliente" (Antônio Roberto Oliveira).

Nesse contexto, entende-se que a correlação entre branding e marca está na maneira como a segunda tem sido gerida pelos conceitos do primeiro. Para Cameira (2013) esta gestão é, na atualidade, marcada pelo aumento da complexidade do 
projeto. A ideia de complexidade e a maneira de lidar com ela é proposta também por Moraes (2010, p.65) como parte da atuação do designer no cenário contemporâneo, cabendo a este profissional a "capacidade permanente de atualização e de gestão da complexidade". O branding é, nesse sentido, uma maneira de gerenciar uma série de fatores próprios da marca no cenário da atualidade.

Mesher (2011) relata o surgimento do branding "por volta de 1880, quando começaram a aparecer logotipos nas embalagens dos alimentos, como sopa Campbell, a Coca Cola e o xarope Lyle's Golden Syrup" ${ }^{1}$ (MESHER, Ibid., p.14). A atuação da publicidade foi ampliada no final da década de 1940, quando a aplicação do branding deixou de ser apenas relacionada ao produto e passou a expressar também a atividade e a função da organização. Com isso, difundiu-se o termo "identidade de marca" no vocabulário corporativo.

Segundo a pesquisadora, foi na década de 1980 que o conceito de branding se consolidou graças à gradativa substituição da valorização do processo de produção pela estratégia de desenvolvimento da essência de marca. Uma desaceleração no mercado ocorreu na década seguinte. Nesse contexto, observou-se a sobrevivência e consolidação das marcas que mantiveram seus valores nas estratégias de marketing. Enquanto isso, o contrário aconteceu com as organizações que deixaram de investir em publicidade, tendo como consequência a "morte da marca", conforme descreve Mesher (Ibid.).

Para Lindstrom (2007), o tema marca é particularmente importante para as organizações nos dias atuais. Ao considerar a nova lógica do consumo - o consumidor mais consciente, o surgimento de novas tecnologias e a compra com ênfase na produção de sentido - faz-se necessário que a marca amplie suas funções e modos de abordagem. Além de representantes de produtos e serviços, ela se torna um recurso dotado de valor autônomo.

Compreender e transitar dentro do universo contemporâneo da comunicação comercial é uma necessidade das marcas atuais. Conforme Semprini (2006), é especialmente a partir dos anos 1980 que a comunicação passou a empreender uma transformação reforçada devido à comunicação de massa e à complexidade crescente da sociedade - algo que requereu o estabelecimento de novas formas de contato para conquistar o consumidor. A comunicação comercial começou exaltar valores imateriais e, nesse cenário, as marcas passaram a ser vistas como enunciadoras das organizações na concretização de projetos de sentido. Desde então, sua identidade se manifesta não somente nos produtos e serviços, mas também em níveis do sensível, pertencente ao mundo das experiências.

A marca contemporânea é dinâmica, evolutiva. À medida que vai sendo construída, se desconecta da materialidade do produto para produzir sentidos mais abrangentes. Para Desserti (2007), a marca assume a função de geradora de identidade, do produto e da organização, um suporte linguístico que se relaciona com os espaços sociais. Semprini (Ibid.) afirma que surge uma nova lógica de marca que a liberta da dimensão comercial e estende sua influência para o discurso social. Torna-se um modo de organização de valores mais eficaz e flexível que atinge esferas políticas e culturais. Para o pesquisador, essa ligação da marca com a configuração comunicacional a oportuniza um espaço central na sociedade contemporânea e nas organizações.

\footnotetext{
${ }^{1}$ Tradução livre.
} 
A fim de compreender o contexto de gestão de marca trazidos por Lindstrom (2007), Mesher (2011) e Wheeler (2008), o presente artigo segue oferecendo uma compilação dos escritos desses autores. Lindstrom é publicitário e consultor de marketing. Destaca-se pelos estudos sobre marcas sensoriais e pelas pesquisas em neuromarketing sobre por que as pessoas compram. Lynne Mesher possui formação em design (de móveis e produto) e atua na área de design de interiores nos setores de varejo e lazer para marcas internacionalmente conhecidas. É docente, pesquisadora e possui publicações nas áreas de ensino de interiores, processo de design, ambientes comerciais e ambientes experienciais. Alina Wheeler é designer, consultora e conferencista que trabalha junto a equipes de gerenciamento e criação em empresas. A essência das ideias propostas pelos autores são apresentadas nos itens 2.1, 2.2 e 2.3 baseando-se unicamente nos escritos em estudo: Lindstrom (2007), Mesher (2011) e Wheeler (2008), respectivamente.

\subsection{Conceitos por Lindstrom (2007)}

A cada ano, o consumidor é exposto a uma variedade excessiva de ofertas e marcas. Em meio a tantos apelos, cabe à publicidade e ao marketing encontrar formas relevantes de abordagem e relação. É neste contexto que Lindstrom (2007) introduz as marcas sensoriais, ou Brandsense. Partindo do pressuposto de que os indivíduos compreendem o mundo através dos sentidos, o pesquisador afirma que o diferencial destas marcas no mercado está em serem planejadas considerando dimensões sensoriais que estabelecem um vínculo emocional com consumidor. Elas oportunizam colocá-lo em contato com suas memórias, estimulando seu lado irracional no ato da compra.

Você lembra da compra de seu primeiro carro novo? O cheiro de carro
novo era inconfundível. Muitas pessoas citam esse cheiro como um
dos aspectos mais gratificantes da compra de um carro novo. O cheiro
é tão significativo quanto o brilho de sua carroceria (LINDSTROM,
2007 , p. 25)

Segundo Lindstrom (Ibid.), ao explorar os sentidos humanos, as marcas se veiculam à memória dos consumidores, atingindo diretamente suas emoções. No que diz respeito ao olfato, por exemplo, o cheiro se conecta às lembranças. A audição relaciona-se ao som e este cria o ânimo. $O$ tato oportuniza o contato, o toque, e se liga diretamente ao bem estar. No paladar está a importância do sabor, do prazer e, por assim dizer, do humor. A visão impacta, cria a primeira impressão e estabelece a diferenciação.

A marca sensorial comunica sua identidade nos pontos de contato com o consumidor através de imagens, cores, formatos, sons, texturas, formas de utilização dos produtos, atendimento, entre outras ações. Cada uma é desenvolvida com o intuito de fortalecer o posicionamento da marca, atuando sozinha ou integrada a outras estratégias. Lindstrom (Ibid.) orienta que, à medida que as organizações investem em um plano de gestão de suas marcas, torna-se igualmente relevante investir em um plano sensorial para elas.

O branding sensorial (LINDSTROM, Ibid., p. 116), como o próprio nome indica, compreende o planejamento e gestão de marcas sob o ponto de vista sensorial, com o objetivo de estabelecer um compromisso emocional com o consumidor. A criação de estratégias origina-se de uma profunda análise sobre a marca e leva em conta uma 
auditoria sensorial, a montagem da marca, a dramatização da marca, a assinatura da marca, a implementação e avaliação da marca sensorial.

A auditoria sensorial da marca consiste no levantamento de informações sobre seu posicionamento, seus consumidores e concorrentes. Também avalia a marca sob o ponto de vista sensorial identificando e monitorando pontos de contato sensoriais existentes. A montagem da marca consiste em dar atenção à sinergia sensorial da marca (LINDSTROM, 2007). Ou seja, seus pontos de contato devem ser planejados para funcionar em sintonia e, assim, fortalecer o efeito da comunicação.

O planejamento do branding sensorial também requer conhecer a personalidade da marca - sua dramatização. Segundo Lindstrom (Ibid.), consiste em identificar os sentimentos e emoções ligados à marca para então transformá-los em apelos sensoriais. A assinatura da marca, por sua vez, é sua "declaração exclusiva" (LINDSTROM, Ibid., p. 134), a personalidade que a diferencia a partir de estados de humor e de atitude.

A quinta etapa do branding sensorial diz respeito à implementação da marca propriamente dita e envolve pesquisas e desenvolvimento de ações dirigidas às dimensões sensoriais. Por fim, o branding sensorial propõe uma avaliação da marca, tarefa que envolve uma análise crítica das estratégias implementadas, considerando em que grau a marca sensorial alcançou o efeito desejado sem perder sua autenticidade.

A gestão de marcas sob o ponto de vista sensorial oportuniza altos níveis de fidelidade do consumidor em um contexto mercadológico saturado por apelos publicitários. Ao considerar a ampliação das marcas em arquiteturas cada vez mais complexas e desvinculadas dos produtos de origem, o branding sensorial auxilia na criação de uma plataforma única, calcada em um vínculo emocional capaz de transitar em diferentes mercados, consumidores e linhas de mercadorias. Conforme Lindstrom (Ibid.), os profissionais de marketing que reconhecerem o poder dos sentidos encontrarão novos meios para construir um vínculo duradouro com seus clientes baseado no prazer e na apreciação oportunizados pelas marcas sensoriais.

\subsection{Conceitos por Mesher}

Mesher (2011) descreve o projeto de interiores comerciais como um processo complexo, que requer análise da marca e sua identidade na etapa inicial. As lojas são locais que devem atrair, entusiasmar e seduzir os consumidores através de uma experiência com a qual possam se identificar, complementa. Em vista disso, o pleno conhecimento da marca torna-se imprescindível para o brandscaping ${ }^{2}$. Tal projeto, que leva em conta o branding, também é caracterizado pela necessidade de constante atualização, para que os ambientes mantenham-se competitivos, seguindo os modismos e as aspirações de seu público.

Em "Diseño de espacios comerciales", Mesher (Ibid.) aborda os processos e estratégias projetuais de interiores comerciais, sendo o primeiro capítulo destinado a branding e identidade. A pesquisadora expõe sobre a relevância da transferência da marca ao espaço tridimensional. Nessa perspectiva, apresenta (i) o conceito e os princípios de branding, (ii) processo de desenvolvimento da marca e sua aplicação no

\footnotetext{
${ }^{2}$ Brandscaping é termo em inglês que se utiliza para definir a representação de uma marca através de um ambiente (MESHER, 2011, p.19)
} 
ambiente e (iii) os mecanismos de promoção e consolidação de uma marca no mercado global. Uma síntese dessa seção é exposta a seguir.

Branding, de acordo com a autora, é uma técnica utilizada para atrair um público específico com o intuito de vender produtos e serviços sob um determinado nome. "Uma marca pode ser um produto, uma pessoa ou um logotipo: qualquer coisa que se possa comprar ou vender, como uma ideia ou artefato, pode ser convertido numa marca" ${ }^{3}$ (MESHER, Ibid., p.12). Além disso, afirma que o branding é sustentado pelo consumismo e a necessidade humana de definir e expressar um estilo de vida através de suas compras. Por esse motivo, o branding está fundamentalmente relacionado à publicidade e ao marketing aplicados à aproximação das aspirações subconscientes dos consumidores.

Em contrapartida, nenhuma marca é atrativa a todos, pondera Mesher (Ibid.). Para que ocorra a identificação entre uma marca e o público ao qual é direcionada, há um trabalho de marketing e publicidade que inicia pela definição dessa marca através da análise dos valores da organização que representa. Esse processo consiste num profundo conhecimento do produto e de como dirigi-lo ao público adequado, além do estudo desses consumidores. Ao final desse processo, o espaço comercial deve ser projetado de forma a transmitir e enaltecer os valores da marca, com o intuito de favorecer a identificação e a relação entre ela e a mensagem, o produto e consumidor.

Para Mesher, "Toda imagem de marca se cria a partir da definição dos princípios fundamentais de seu significado" ${ }^{4}$ (MESHER, Ibid., p.15). Tais princípios consideram o produto e o contexto de inserção, ou seja, conhecer os concorrentes com o intuito de posicionar a marca. A partir desse estudo, os objetivos organizacionais são evidenciados e a estratégia de marca estabelecida. De acordo com a autora, a análise dos princípios de uma marca abarca: (i) a essência, que representa as principais características da organização, considerando a atividade e a natureza do trabalho; (ii) os valores, que requer o estudo dos princípios morais corporativos e a como são transmitidos na marca; (iii) a imagem, que expressa a essência e os valores organizacionais através de meios visuais, elemento de extrema relevância no desenvolvimento da marca; (iv) as grandes ideias, que revelam os objetivos da marca; (v) a geração de lucro; (vi) a atração de novos consumidores e (vii) a cultura, que envolve o questionamento sobre o mercado consumidor pretendido.

Mesher (Ibid.) explica que, geralmente, as organizações contratam consultores de marca para gerenciar o processo de desenvolvimento ou reinvenção de uma marca, pois isso exige conhecimentos específicos. Segundo a pesquisadora, esse processo inicia com investigação e análise da natureza da organização e de sua caracterização, ponderando sua posição atual. Para uma melhor definição do posicionamento da empresa no mercado, os principais concorrentes também podem ser analisados nessa fase.

A etapa seguinte envolve os designers gráficos, que "contextualizam os diferentes significados implícitos na ideia central, e se questionam acerca da imagem e a sensação que transmite a marca" ${ }^{5}$ (MESHER, Ibid., p.18). Para definição da imagem da marca, são elaborados painéis de inspiração (mood boards) e de estilo de vida (lifestyle boards). A partir disso, é possível determinar um estilo que fundamentará

\footnotetext{
${ }^{3}$ Tradução livre.

${ }^{4}$ Tradução livre.

${ }^{5}$ Tradução livre.
} 
tanto o projeto de design gráfico, como o projeto design de interiores. Nesse momento, designers gráficos e de interiores trabalham de forma colaborativa.

As decisões do projeto gráfico envolvem a representação da marca na publicidade. Para tanto, é desenvolvido um manual de identidade corporativa (brand guidelines), que preconiza a coerência da comunicação visual, sua aplicação no ambiente comercial e nos acabamentos aplicados nesse espaço, esclarece Mesher (Ibid.). Dessa forma, a partir do manual de identidade corporativa, as aspirações do consumidor pretendido e a postura competitiva que se pretende adotar, o projeto de interiores é elaborado.

Painéis de inspiração apoiam a investigação visual necessária no processo projetual de brandscaping, complementa Mesher (Ibid.). Para viablizar a aplicação da marca num ambiente é essencial: (i) identificar a marca e suas cores, motivos, logotipos, sons e aromas associados; (ii) entender o produto e seus possíveis consumidores e (iii) analisar o estilo de vida das pessoas que poderiam utilizar essa marca, bem como, identificar o que esperam de uma experiência de compra no ambiente em projeto. Para dar continuidade ao projeto, são elaboradas simulações das ideias geradas através de storyboards (série de imagens organizadas em sequência para oferecer a pré-visualização de um projeto). Para implantar o projeto (roll out), a equipe de design desenvolve um manual para padronização das lojas em diferentes lugares.

Por fim, Mesher (Ibid.) apresenta os mecanismos de promoção e consolidação de uma marca no mercado global, classificados em: (i) lojas conceito (concept stores), onde se novas ideias comerciais são testadas ou promovidas; (ii) lojas próprias (flagship stores), onde a marca é promovida em grandes zonas comerciais; (iii) lojas de estilo de vida (lifestyle stores), onde uma ampla gama de produtos de setores distintos é oferecida como forma de representação de um modo de vida representado pela marca e (iv) lojas ou instalações temporárias (pop-up), uma estrutura efêmera que permanece em determinado local por um período de tempo reduzido. E esclarece que tais estratégias são realizadas em locais relevantes, com o intuito de alcançar a maior parte dos consumidores possível, para depois o projeto ser reinterpretado em lojas menores.

\subsection{Conceitos por Wheeler (2008)}

Alina Wheeler (2008, p.12) define marca como "a promessa, a grande ideia e as expectativas que residem na mente de cada consumidor à respeito de um produto, de um serviço ou de uma empresa". A pesquisadora faz essa afirmação após explanar que a marca se encontra como elemento de competição pelo reconhecimento, sendo este não mais restrito ao terreno físico, mas evoluído para a concorrência do share of mind, ou seja, o espaço do reconhecimento pela mente do consumidor. Neste contexto, o presente artigo segue apresentando alguns dos conceitos expressos por Wheeler em "Design de identidade da marca", dando especial atenção às visões da autora com relação aos processos que envolvem a gestão de marcas e as iniciativas requeridas na construção de uma identidade de marca bem sucedida.

Por identidade, Wheeler compreende aquilo que é tangível e também aquilo que apela para os sentidos. Consiste na expressão visual e verbal de uma marca que pode ser vista, tocada, agarrada, ouvida, observada e movida. Quando é de fácil memorização e imediatamente reconhecível, a identidade viabiliza a conscientização e 
o reconhecimento da marca. Esta torna-se intrínseca na cultura de uma organização na medida em que é uma lembrança constante de seus valores fundamentais e de sua tradição.

Reforçando tal pensamento, Wheeler (Ibid., p. 19) cita as aspirações de identidade desenvolvidas pela estrategista de design da informação, Sylvia Harris, que pontua que a identidade é capaz de: "expressar que espécie de organização você é"; "garantir ao público que você é realmente aquilo que diz ser"; "conectar sua empresa a imagens e ideias"; "servir como fio condutor para construir patrimônio ao longo do tempo", "proporcionar consistência nos canais de comunicação".

Tornar "a compra mais fácil para o consumidor", fazer "com que, para a equipe de vendas, seja mais fácil vender" e permitir que seja "mais fácil a construção de brand equity" são razões para investir na identidade de marca, segundo Wheeler (Ibid., p.23). A compreensão por parte do consumidor sobre as vantagens e benefícios de uma marca garante mais respeito, sendo isso uma consequência da identidade, pois ela ajuda a gerenciar a percepção de uma organização e a diferencia-la de seus concorrentes.

A venda de uma imagem de marca estrategicamente pensada não somente funciona entre diferentes públicos, mas também, contribui para que a própria organização tenha ciência de seu potencial. Isso se dá também por meio do brand equity, ou seja, o valor da marca no que tange a sua reputação positiva, aquilo que está além do patrimônio físico de uma empresa, por exemplo.

0 desafio dos estudos que envolvem o branding tem sido entender o que fazem algumas marcas se destacarem em meio a tantas outras. Wheeler defende que a excelência no design é um dos requisitos para tanto e que as melhores identidades são mais eficientes na impulsão da empresa através da marca. Para a autora, melhores identidades significam, entre outros quesitos, aquelas que visualmente seguem critérios funcionais adequados e características como audácia, memorização, adequação e reconhecimento imediato; conceitos que apresentam uma imagem clara e consistente para a empresa e comunicam a sua personalidade.

Wheeler (Ibid., p.25) também defende que a visão geral dos ideais de uma marca podem ser resumida em nove itens inter-relacionados: visão; significado; autenticidade; diferenciação; sustentabilidade; coerência; flexibilidade; comprometimento; valor. Isso constitui uma marca que é movida por uma visão estimulante; que significa um conjunto de valores positivos; que é autêntica e clara no que se refere ao mercado de atuação; que diferencia-se de seus concorrentes; que tem posição sustentável em termos de longevidade; que tem coerência nas experiências dos consumidores; que é flexível para mudanças voltadas ao crescimento futuro; que se compromete no cuidado com as diversas variáveis gerenciais; que pode ser medida em termos de valor agregado.

No que se refere à experiência das pessoas com a marca, Wheeler entende que cada oportunidade com o consumidor é um momento de realçar uma conexão emocional. Para a pesquisadora, a grande quantidade de opções de compra estão induzindo as marcas a verem no planejamento de experiências um meio para seduzir o público. Neste sentido, a eficaz estratégia de marca tem sido aquela que funciona, através de produtos e serviços, pela união de conceitos de comportamento, ações e comunicações adequados. Em suma, as melhores estratégias são aquelas que 
consistem em uma profunda compreensão das necessidades e percepções dos consumidores alinhando-se à ações de marketing em ressonância com os stakeholders.

\section{ANÁLISE COMPARATIVA}

Um aprofundamento nos escritos de Lindstrom (2007), Mesher (2011) e Wheeler (2008), demonstrou que os autores convergem em alguns pontos e que, mesmo com enfoques diferentes quanto à abordagem da temática - gestão de marca ou branding - conceitos similares podem ser reconhecidos em seus textos. Desconsiderando descrições que apontavam ações específicas - tais como exemplos, ferramentas ou maneiras de fazer algo - o estudo levantou seis pontos afins entre os conceitos apresentados pelos autores e que foram resumidos nas seis sentenças a seguir: (i) Linguagem organizada que faça sentido; (ii) Marca como vínculo emocional; (iii) Marca como meio de sobrevivência; (iv) Algum diferencial que atraia; (v) Meios que tangibilizem conceitos; (vi) Design e marketing como aliados.

A fim de compreender os pontos de convergência, as sentenças foram expressas em forma de quadro (Quadro 1), sendo que a coluna denominada "Conceitos convergentes" se refere às sentenças, ou seja, ao resultado da correlação entre os conceitos de gestão de marca ou branding trazidos pelos três autores.

Quadro 1 - Análise comparativa

\begin{tabular}{|c|c|c|c|}
\hline $\begin{array}{l}\text { CONCEITOS } \\
\text { CONVERGENTES }\end{array}$ & LINDSTROM (2007) & MESHER (2011) & WHEELER (2008) \\
\hline $\begin{array}{l}\text { Linguagem } \\
\text { organizada que } \\
\text { faça sentido }\end{array}$ & $\begin{array}{l}\text { As estratégias sensoriais } \\
\text { da marca devem ser } \\
\text { planejadas em sinergia e } \\
\text { considerando a "herança } \\
\text { da marca", isto é, sua } \\
\text { essência. }\end{array}$ & $\begin{array}{l}\text { O projeto de um } \\
\text { ambiente comercial é } \\
\text { desenvolvido em torno do } \\
\text { conceito da marca e dos } \\
\text { produtos que serão } \\
\text { vendidos. A loja se iguala } \\
\text { aos valores e às } \\
\text { qualidades que a marca } \\
\text { aspira, com o objetivo de } \\
\text { destacar a relação } \\
\text { coerente entre o espaço e } \\
\text { a mensagem, reafirmando } \\
\text { o valor da marca. }\end{array}$ & $\begin{array}{l}\text { A mensagem é o mantra da } \\
\text { marca e funciona bem } \\
\text { quando destila a essência } \\
\text { do produto ou serviço. A } \\
\text { mensagem vem através da } \\
\text { linguagem que precisa ser } \\
\text { viva, direta, eloquente e } \\
\text { substanciosa. }\end{array}$ \\
\hline $\begin{array}{l}\text { Marca como } \\
\text { vínculo } \\
\text { emocional }\end{array}$ & $\begin{array}{l}\text { O branding sensorial } \\
\text { oportunizará um } \\
\text { compromisso emocional } \\
\text { com o consumidor } \\
\text { gerando níveis mais altos } \\
\text { de fidelidade por colocá- } \\
\text { los em contato com suas } \\
\text { memórias e o lado menos } \\
\text { racional no ato da } \\
\text { compra. }\end{array}$ & $\begin{array}{l}\text { O branding é sustentado } \\
\text { pelo consumismo e a } \\
\text { necessidade humana de } \\
\text { definir e expressar um } \\
\text { estilo de vida através de } \\
\text { suas compras. Seja para } \\
\text { alimentação, vestuário ou } \\
\text { lazer, comprar é uma } \\
\text { atividade cotidiana. Os } \\
\text { produtos e locais } \\
\text { escolhidos refletem o } \\
\text { estilo de vida, a cultura e } \\
\text { os interesses de uma } \\
\text { pessoa, que estabelece } \\
\text { um vínculo emocional } \\
\text { com o contexto comercial } \\
\text { no qual se sente a } \\
\text { vontade. }\end{array}$ & $\begin{array}{l}\text { Quando as pessoas se } \\
\text { apaixonam por uma } \\
\text { determinada marca são } \\
\text { fiéis a ela e acreditam na } \\
\text { sua superioridade e essa } \\
\text { fidelidade é construída em } \\
\text { cada ponto de contato da } \\
\text { empresa com o } \\
\text { consumidor, em momentos } \\
\text { onde a marca oportuniza } \\
\text { que se realcem conexões } \\
\text { emocionais. }\end{array}$ \\
\hline
\end{tabular}




\begin{tabular}{|c|c|c|c|}
\hline $\begin{array}{l}\text { Marca como } \\
\text { meio de } \\
\text { sobrevivência }\end{array}$ & $\begin{array}{l}\text { Marcas sensoriais se } \\
\text { diferenciam em um } \\
\text { contexto mercadológico } \\
\text { saturado por apelos } \\
\text { publicitários. No contexto } \\
\text { de arquiteturas de marca } \\
\text { cada vez mais complexas } \\
\text { e desvinculadas dos } \\
\text { produtos de origem, o } \\
\text { branding sensorial auxilia } \\
\text { na criação de uma } \\
\text { plataforma única } \\
\text { (emocional) capaz de } \\
\text { transitar em diferentes } \\
\text { mercados, consumidores } \\
\text { e linhas de produto. }\end{array}$ & $\begin{array}{l}\text { A identificação das } \\
\text { pessoas com } \\
\text { determinadas marcas } \\
\text { fideliza o consumo, } \\
\text { independente do preço } \\
\text { dos produtos. As marcas } \\
\text { são identificadas e } \\
\text { vendidas ao público } \\
\text { através do marketing e da } \\
\text { publicidade. Uma } \\
\text { organização que deixara } \\
\text { de investir em publicidade } \\
\text { corre o risco de não } \\
\text { sobreviver no mercado. }\end{array}$ & $\begin{array}{l}\text { Marcas ineficazes debilitam } \\
\text { o negócio, enquanto a } \\
\text { diferenciação leva ao bom } \\
\text { posicionamento e se torna } \\
\text { determinante para } \\
\text { sobreviver em um meio } \\
\text { povoado de marcas. A } \\
\text { sobrevivência de uma } \\
\text { empresa está diretamente } \\
\text { relacionada ao } \\
\text { reconhecimento positivo } \\
\text { por parte do consumidor e } \\
\text { a gestão da marca é } \\
\text { determinante neste } \\
\text { contexto. }\end{array}$ \\
\hline $\begin{array}{l}\text { Algum } \\
\text { diferencial que } \\
\text { atraia }\end{array}$ & $\begin{array}{l}\text { O branding sensorial } \\
\text { diferencia-se pelas } \\
\text { estratégias sensoriais que } \\
\text { relaciona o consumidor a } \\
\text { uma experiência } \\
\text { emocional com a marca. }\end{array}$ & $\begin{array}{l}\text { As lojas conceito (concept } \\
\text { stores), lojas próprias } \\
\text { (flagship stores), lojas de } \\
\text { estilo de vida (lifestyle } \\
\text { stores) e as instalações } \\
\text { temporárias (pop-up) são } \\
\text { estratégias de promoção } \\
\text { e consolidação de uma } \\
\text { marca no mercado global } \\
\text { através do design de } \\
\text { interiores. }\end{array}$ & $\begin{array}{l}\text { A empresa precisa } \\
\text { diferenciar-se de seus } \\
\text { concorrentes para obter } \\
\text { uma fatia maior de } \\
\text { mercado. Esse diferencial } \\
\text { pode estar no estilo do } \\
\text { serviço oferecido pela } \\
\text { marca e no uso da } \\
\text { identidade para criar polos } \\
\text { de atração sensoriais que } \\
\text { captem e fixem } \\
\text { consumidores. }\end{array}$ \\
\hline $\begin{array}{l}\text { Meios que } \\
\text { tangibilizem } \\
\text { conceitos }\end{array}$ & $\begin{array}{l}\text { O branding sensorial deve } \\
\text { se fazer presente de } \\
\text { forma consistente e nos } \\
\text { pontos de contato com o } \\
\text { consumidor, como lojas, } \\
\text { embalagens, produtos, } \\
\text { peças e ações publicitárias }\end{array}$ & $\begin{array}{l}\text { O brandscaping preconiza } \\
\text { identificar as } \\
\text { características associadas } \\
\text { à imagem da marca e o } \\
\text { estilo de vida que ela } \\
\text { pretende transmitir na } \\
\text { elaboração do projeto de } \\
\text { interiores. Desse modo, } \\
\text { elementos de } \\
\text { comunicação visual, } \\
\text { iluminação, revestimentos } \\
\text { (cores, motivos e } \\
\text { texturas), música e } \\
\text { aromas tangibilizam a } \\
\text { marca no espaço. }\end{array}$ & $\begin{array}{l}\text { A identidade visual é um } \\
\text { dos fatores que ajudam a } \\
\text { impulsionar uma marca e } \\
\text { essa identidade se } \\
\text { tangibiliza na expressão } \\
\text { visual e em produtos e } \\
\text { serviços que demonstram } \\
\text { critérios funcionais como } \\
\text { reconhecimento imediato, } \\
\text { memorização, imagem } \\
\text { clara e consistente, } \\
\text { personalidade, entre } \\
\text { outros. }\end{array}$ \\
\hline $\begin{array}{l}\text { Design e } \\
\text { marketing } \\
\text { como aliados }\end{array}$ & $\begin{array}{l}\text { No branding sensorial o } \\
\text { marketing é um } \\
\text { importante aliado na } \\
\text { criação e implementação } \\
\text { de estratégias de } \\
\text { aproximação com o } \\
\text { consumidor através das } \\
\text { ferramentas de } \\
\text { promoção: publicidade, } \\
\text { relações públicas, venda } \\
\text { direta, entre outros. }\end{array}$ & $\begin{array}{l}\text { O branding está } \\
\text { essencialmente } \\
\text { relacionado à publicidade } \\
\text { e ao marketing aplicados } \\
\text { na interpretação das } \\
\text { aspirações subconscientes } \\
\text { dos consumidores. }\end{array}$ & $\begin{array}{l}\text { O marketing dirige a gestão } \\
\text { da marca no contexto da } \\
\text { cultura organizacional e } \\
\text { através de ações específicas } \\
\text { nas quais o design tem } \\
\text { papel fundamental de } \\
\text { articulação dos fatores que } \\
\text { ligam a marca ao seu } \\
\text { público. }\end{array}$ \\
\hline
\end{tabular}

Fonte: Elaborado pelas autoras com base na pesquisa realizada.

A sentença "linguagem organizada que faça sentido" se refere a um conjunto de estratégias a serem gerenciadas pela marca, sendo que essas devem remeter a sensações que toquem o público, ao mesmo tempo que reafirmam valores positivos. $A$ 
essência da marca está, justamente, na comunicação que ela estabelece com os seus admiradores e esta ocorre por meio de uma linguagem bem estabelecida. Nesse sentido, falar de "marca como vínculo emocional" é também remeter ao canal de comunicação e às linguagens múltiplas. Essas, no entanto, em todos os aspectos intangíveis que a marca permite experienciar. O resultado é o estreitamento emocional da relação entre o público e todos os pontos de contato propiciados pela marca.

O branding é determinante para a gestão de um processo inserido em um contexto mercadológico saturado. Pensar na "marca como meio de sobrevivência" é estar ciente que transitar por diferentes mercados requer consciência e trabalho árduo, mas somente desta forma - e através de adequada gestão de marca - é possível sobressair-se. O público está em busca de "algum diferencial que atraia", não por falta de opção em termos de quantidade de produtos ou serviços a ele disponibilizados, mas porque muitas vezes há carência de atrativos sensoriais. 0 diferencial é, desta forma, a maneira de conquista em meio ao excesso no mercado, a forma de relacionar-se com o público através de produtos e serviços que promovam novidades, experiências positivas e emoções agradáveis.

O reconhecimento imediato, a memorização, imagem clara e consistente e personalidade são resultados de uma marca bem trabalhada e tais são perceptíveis através dos conceitos que produtos e serviços sensorialmente emitem. Buscar "meios que tangibilizem conceitos" é ter a ciência que os melhores produtos e serviços devem estar contidos de conceitos substanciosos que são alimentos por ele. Neste sentido, "design e marketing são aliados" na construção do elo entre o conceito, o produto e o serviço que estrutura a marca em si. Design e marketing não se tratam de áreas isoladas uma da outra, mas de campos complementares e interconectados.

\section{CONCLUSÃO}

As sentenças emitidas por meio das análises dos textos de Lindstrom (2007), Mesher (2011) e Wheeler (2008) confirmam a hipótese de que os três autores convergem quanto a alguns conceitos que apresentam, mesmo que seus enfoques em termos de aplicação sejam diferenciados. As ideias trazidas em seus trabalhos se correlacionam, sendo complementares e especialmente afins em seis pontos: (i) Linguagem organizada que faça sentido; (ii) Marca como vínculo emocional; (iii) Marca como meio de sobrevivência; (iv) Algum diferencial que atraia; (v) Meios que tangibilizem conceitos; (vi) Design e marketing como aliados.

A análise que resultou nos seis apontamentos ou sentenças relatados no presente estudo não somente permitiram a visualização das linhas convergentes entre os autores, mas mostraram maneiras particulares com que cada um deles entende o contexto da gestão da marca, ou seja, do branding. Se por um lado foi possível, através do objetivo proposto nessa pesquisa, confrontar seus textos com a intenção de extrair conceitos afins, por outro foi notável que as abordagens diversas, particularizadas nos textos de cada autor, podem ser complementares.

O estudo se concentrou em três publicações que descrevem proposições na área do branding e os escritos de Lindstrom (2007), Mesher (2011) e Wheeler (2008) foram resumidos a breves textos, tais quais relatados neste artigo. Esta síntese pode ser apontada como uma limitação da pesquisa, embora tal tenha sido necessária para que as análises se concretizassem a partir do confronto de conceitos pontuais na 
essência do texto de cada autor. Seguindo a linha desta pesquisa, como continuação em trabalhos futuros sugere-se o estudo de possíveis pontos de discordância entre os autores, assim como, a complementação a partir da análise de outras publicações de relevância na área. Ainda, por integrarem a esta pesquisa uma forma de reflexão aplicada, levantamentos de casos que exemplifiquem os conceitos teóricos trazidos pelos autores estudados seriam, também, ideia de continuação.

\section{REFERÊNCIAS}

CAMEIRA, Sandra Ribeiro. 0 branding e a metodologia de sistemas de identidade visual. 2013. 428 f. Dissertação (Mestrado) - Curso de Design e Arquitetura, Departamento de Faculdade de Arquitetura e Urbanismo, Universidade de São Paulo, São Paulo, 2013. Disponível em: <http://www.teses.usp.br/teses/disponiveis/16/16134/tde-28012014100230/en.php>. Acesso em: 01 maio 2014.

CELASCHI, Flaviano e DESERTI, Alessandro. Design e Innovazione: Strumenti e pratiche per la ricerca applicata. Roma: Carocci. 2007.

LINDSTROM, Martin. Brandsense: a marca multissensorial. Porto Alegre: Bookman, 2007.

MESHER, Lynne. Diseño de espacios comerciales. Barcelona GG, 2011.

MORAES, Dijon de. Metaprojeto como modelo projetual. Strategic Design Research Journal. Porto Alegre, p. 62-68. ago. 2010. Disponível em: <http://revistas.unisinos.br/index.php/sdrj/article/view/4788>. Acesso em: 01 abr. 2014.

FLICK, Uew. Introdução à pesquisa qualitativa. 3. ed. Porto Alegre: Artmed, 2009.

SEMPRINI, Andrea. A marca pós-moderna: poder e fragilidade da marca na sociedade contemporânea. São Paulo: Estação das Letras, 2006.

SILVA, Adriana Costa e. Branding \& Design: Identidade no varejo. Rio de Janeiro: Rio Books, 2002.

STRUNCK, G. Como criar identidades visuais para marcas de sucesso. Rio de Janeiro: Rio Books, 2012.

WHEELER, Alina. Design de identidade da marca: um guia completo para criação, construção e manutenção de marcas fortes. Porto Alegre: Bookman, 2008. 